\title{
Extraction of antioxidant phenolic compounds from spent coffee grounds
}

\author{
Solange I. Mussatto*, Lina F. Ballesteros, Silvia Martins, José A. Teixeira \\ Institute for Biotechnology and Bioengineering (IBB), Centre of Biological Engineering, University of Minho, Campus de Gualtar, $4710-057$ Braga, Portugal
}

\section{A R T I C L E I N F O}

\section{Article history:}

Received 1 May 2011

Received in revised form 11 September 2011

Accepted 22 September 2011

Available online 1 October 2011

\section{Keywords:}

Antioxidant activity

Extraction

Methanol

Phenolic compounds

Spent coffee grounds

\begin{abstract}
A B S T R A C T
The extraction of antioxidant phenolic compounds from spent coffee grounds (SCG) was studied. Extraction experiments were carried out by the conventional solid-liquid method, using methanol as solvent at different concentrations (20-100\%), solvent/solid ratios (10-40 ml/g SCG), and extraction times (30$90 \mathrm{~min}$ ), and the influence of these operational variables on the content of total phenolic compounds and antioxidant activity of the produced extracts was evaluated. Flavonoids, chlorogenic acid, and protocatechuic acid were found in all the produced extracts and were also quantified. A strong influence $(p<0.05)$ of the variables on the extraction results was verified, and the conditions able to maximize each response (contents of total phenolic compounds, flavonoids, chlorogenic acid and protocatechuic acid, and antioxidant activity) were established. Extraction using $60 \%$ methanol in a solvent/solid ratio of $40 \mathrm{ml} / \mathrm{g} \mathrm{SCG}$, during $90 \mathrm{~min}$, was the most suitable condition to produce a extract with high content of phenolic compounds ( $16 \mathrm{mg}$ gallic acid equivalents/g SCG) and high antioxidant activity (FRAP of $0.10 \mathrm{mM} \mathrm{Fe}(\mathrm{II}) / \mathrm{g})$, simultaneously. These findings are of interest since antioxidant phenolic compounds have an outstanding role in health area, and wide applications in food and pharmaceutical products.
\end{abstract}

(c) 2011 Elsevier B.V. All rights reserved.

\section{Introduction}

In the last years, the instant coffee industry has experienced a constant growth as instant coffee has become one of the most popular kinds of coffee drunk by million of people around the world. As a consequence, large amounts of spent coffee grounds (SCG), which are the solid residues obtained during the processing of coffee powder with hot water or steam to prepare instant coffee, have been generated worldwide (in the order of 6,000,000 tons/year) $[1,2]$. Although the large availability and composition rich in compounds of industrial interest such as carbohydrates, proteins, and phenolic compounds [3], SCG has not been used as raw material for other processes.

Phenolic compounds have received considerable attention due to their beneficial effects on human health, such as a protective action against chronic degenerative diseases (cataracts, macular degeneration, neurodegenerative diseases, and diabetes mellitus), cancer and cardiovascular diseases, and others [4]; which have been ascribed to their antioxidant activity [5]. In a recent study, extracts produced from SCG exhibited anti-tumor and anti-allergic activities, which were related to the presence of phenolic compounds such as chlorogenic acid in their composition [6]. In fact, chlorogenic acid, which is one of the most abundant phenolic compounds in SCG [6,7], has been reported to have a number of beneficial health properties related to their potent antioxidant activity

\footnotetext{
* Corresponding author. Tel.: +351 253604 424; fax: +351 253604429 .

E-mail addresses: solange@deb.uminho.pt, solangemussatto@hotmail.com (S.I. Mussatto).
}

as well as hepatoprotective, hypoglycemic, anti-bacterial, antiviral, anti-inflammatory and anti-carcinogenic activities [8,9]. Due to these important biofunctionalities, phenolic compounds have found numerous applications in food and pharmaceutical areas. Extracting antioxidant phenolic compounds from SCG can be thus considered an interesting alternative to obtain these important industrial ingredients from a low cost raw material, while add value to SCG.

Extraction is the first step in the isolation of phenolic compounds from agro-industrial residues and plant materials. Different techniques have been applied to recover antioxidant phenolic compounds from natural sources including solid-liquid extraction with organic solvents, ultrasound-assisted extraction, microwaveassisted extraction, supercritical fluids extraction, and high pressure processes [10-12]. Among these techniques, solid-liquid extraction is widely employed for phenolics extraction from vegetable sources. However, the efficiency of the extraction process is affected by several factors such as the type of solvent and its concentration, the solvent/solid ratio, the number of extraction steps, $\mathrm{pH}$, time of contact, temperature, and particle size of the solid matrix [13-15]. Thus, it is very important to optimize the extraction conditions in order to maximize the extraction efficiency to each raw material.

The objective of this study was to extract antioxidant phenolic compounds from SCG. Solid-liquid extractions were performed using methanol as solvent, due to its wide use in different processes, and recognized efficiency for phenolic compounds extraction from plant materials. Additionally, aqueous methanol has a high boiling point, and is an economical solvent [16]. Different 
methanol concentrations, solvent/solid ratios, and extraction times were studied, and the effect of these operational variables on the extraction results was verified. Moreover, the conditions able to produce a phenolic rich extract with high antioxidant activity were established.

\section{Materials and methods}

\subsection{Sample material and chemicals}

Spent coffee grounds (SCG) were supplied by NovaDelta-Comércio e Indústria de Cafés S.A. (Campo Maior, Portugal). The material was dried in an oven at $60{ }^{\circ} \mathrm{C}$ until $5 \%$ moisture content and stored for further extractions. Phenolic standards including gallic acid, chlorogenic acid, protocatechuic acid, and quercetin; methanol and Folin-Ciocalteu phenol reagent were purchased from Sigma (Sigma-Aldrich GmbH, Sternheim, Germany). All other chemicals used were of analytical grade and obtained from either Sigma-Aldrich or Merck (Darmstadt, Germany).

\subsection{Solvent extraction}

In a first stage, the extraction experiments were performed using different conditions of methanol concentration (60-100\%), solvent/solid ratio $(10-30 \mathrm{ml} / \mathrm{g})$, and extraction time (30$90 \mathrm{~min})$. The conditions used in each experiment were settled according to the $2^{3}$ full factorial design presented in Table 1 . Subsequently, additional extraction experiments were performed by varying the methanol concentration between $20 \%$ and $80 \%$, and the solvent/solid ratio between 10 and $40 \mathrm{ml} / \mathrm{g} \mathrm{SCG}$, during 90 min (Table 2). For comparison, assays using only distilled water as extraction solvent were also performed.

For the reactions, the extraction solvent and the SCG were poured into $100-\mathrm{ml}$ Erlenmeyer flasks, which were duly covered and maintained during the desired time in a water-bath with magnetic agitation at $60-65^{\circ} \mathrm{C}$. Subsequently, the total content of each flask was centrifuged $\left(2500 \mathrm{~g}, 4^{\circ} \mathrm{C}, 20 \mathrm{~min}\right)$ and the supernatant (SCG extract) was filtered through $0.22 \mu \mathrm{m}$ filters and stored at $-20^{\circ} \mathrm{C}$ in darkness until analyses. The volume of extract recovered after each extraction was quantified and used for calculations.

\section{Table 1}

Experimental conditions used to evaluate the effect of process variables (methanol concentration, time and solvent/solid ratio) on the extraction of antioxidant phenolic compounds from SCG, composition and antioxidant activity of each obtained extract. Assays according to a $2^{3}$ full factorial design.

\begin{tabular}{|c|c|c|c|c|c|}
\hline \multirow[t]{2}{*}{ Assay } & \multicolumn{3}{|c|}{$\begin{array}{l}\text { Process variables - real and (coded) } \\
\text { values }\end{array}$} & \multicolumn{2}{|l|}{ Responses $^{\mathrm{a}}$} \\
\hline & $\begin{array}{l}\text { Methanol } \\
\text { concentration } \\
(\%)\end{array}$ & $\begin{array}{l}\text { Time } \\
(\min )\end{array}$ & $\begin{array}{l}\text { Solvent/solid } \\
\text { ratio }(\mathrm{ml} / \mathrm{g})\end{array}$ & $\begin{array}{l}\text { TP } \\
\text { (mg GAE/ } \\
\text { g SCG) }\end{array}$ & $\begin{array}{l}\text { FRAP } \\
(\mathrm{mM} \mathrm{Fe}(\mathrm{II}) / \\
\text { g SCG) }\end{array}$ \\
\hline 1 & $60(-1)$ & $30(-1)$ & $10(-1)$ & 8.1 & 0.052 \\
\hline 2 & $100(+1)$ & $30(-1)$ & $10(-1)$ & 2.9 & 0.036 \\
\hline 3 & $60(-1)$ & $90(+1)$ & $10(-1)$ & 10.7 & 0.054 \\
\hline 4 & $100(+1)$ & $90(+1)$ & $10(-1)$ & 2.6 & 0.021 \\
\hline 5 & $60(-1)$ & $30(-1)$ & $30(+1)$ & 9.7 & 0.162 \\
\hline 6 & $100(+1)$ & $30(-1)$ & $30(+1)$ & 3.2 & 0.116 \\
\hline 7 & $60(-1)$ & $90(+1)$ & $30(+1)$ & 16.2 & 0.158 \\
\hline 8 & $100(+1)$ & $90(+1)$ & $30(+1)$ & 4.4 & 0.115 \\
\hline 9 & $80(0)$ & $60(0)$ & $20(0)$ & 11.9 & 0.096 \\
\hline 10 & $80(0)$ & $60(0)$ & $20(0)$ & 12.3 & 0.109 \\
\hline 11 & $80(0)$ & $60(0)$ & $20(0)$ & 10.6 & 0.105 \\
\hline 12 & $80(0)$ & $60(0)$ & $20(0)$ & 11.2 & 0.107 \\
\hline
\end{tabular}

a TP: total phenolics; FRAP: antioxidant activity by the ferric reducing antioxidant power assay.

\subsection{Analytical methodology}

\subsubsection{Determination of total phenolics}

The total content of phenolic compounds in SCG extracts was determined by using the Folin-Ciocalteu reagent according to the colorimetric method described by Singleton and Rossi [17], adapted to a 96-well microplate. Briefly, $5 \mu \mathrm{l}$ of each filtered extract were mixed with $60 \mu \mathrm{l}$ of sodium carbonate solution at $7.5 \%$ (w/v) and $15 \mu \mathrm{l}$ of Folin-Ciocalteu reagent. Subsequently, $200 \mu \mathrm{l}$ of distilled water were added and the solutions were mixed. After that, the samples were heated at $60^{\circ} \mathrm{C}$ for $5 \mathrm{~min}$ and were allowed to cool at room temperature. The absorbance was measured by means of a spectrophotometric microplate reader set at $700 \mathrm{~nm}$. A calibration curve was made from a gallic acid standard solution $(200,400,600,800,1000,2000,3000 \mathrm{mg} / \mathrm{l})$ and the blank was prepared with distilled water. The total content of phenolic compounds was expressed as milligram gallic acid equivalent per dry weight material (mg GAE/g SCG).

\subsubsection{Determination of flavonoids}

Flavonoids in SCG extracts were estimated using the colorimetric assay previously described by Chang et al. [18] with some modifications. A volume of $30 \mu \mathrm{l}$ of each filtered extract was added in a 96-well microplate and subsequently, a sequential addition of $90 \mu \mathrm{l}$ methanol, $6 \mu \mathrm{l}$ aluminum chloride at $10 \%(\mathrm{w} / \mathrm{v}), 6 \mu \mathrm{l}$ potassium acetate $(1 \mathrm{~mol} / \mathrm{l})$, and $170 \mu \mathrm{l}$ distilled water to each extract sample was performed. Samples were maintained during $30 \mathrm{~min}$ in the dark at room temperature. The absorbance of the mixture was then measured at $415 \mathrm{~nm}$ against a blank of distilled water. A calibration curve was prepared with a standard solution of quercetin $(25,50,100,150,200 \mathrm{mg} / \mathrm{l})$. The content of total flavonoids was expressed as milligram quercetin equivalent per dry weight material (mg QE/g SCG).

\subsubsection{Determination of antioxidant activity}

The antioxidant activity of SCG extracts was measured by the ferric reducing antioxidant power (FRAP) assay, which was performed according to the method described by Benzie and Strain [19] with some modifications. A $10 \mu \mathrm{l}$ aliquot of filtered extract was mixed with $290 \mu$ of FRAP reagent in a 96-well microplate, and incubated at $37^{\circ} \mathrm{C}$ for $15 \mathrm{~min}$. After that, the absorbance was determined at $593 \mathrm{~nm}$ using distilled water as blank. A calibration curve was constructed using an aqueous solution of ferrous sulfate $\left(\mathrm{FeSO}_{4} \cdot 7 \mathrm{H}_{2} \mathrm{O}\right.$ at $200,400,600,800$ and $\left.1000 \mu \mathrm{M}\right)$. The FRAP values were expressed as millimoles of ferrous equivalent per dry weight of material (mM Fe(II)/g SCG).

\subsubsection{Chlorogenic acid and protocatechuic acid determinations}

Chlorogenic acid and protocatechuic acid were analyzed by high performance liquid chromatography (HPLC) on an equipment LC10 A (Jasco, Japan) using a UV detector at $276 \mathrm{~nm}$ and a Nucleosil 120-5 C18 $5 \mu \mathrm{m}(4.6 \times 250 \mathrm{~mm})$ column at room temperature. A mixture of acetonitrile and water (ratio $1 / 8$ ) with $10 \mathrm{~g} / \mathrm{l}$ of glacial acetic acid and with the final $\mathrm{pH}$ adjusted to 2.5 with phosphoric acid was used as mobile phase at a flow rate of $0.9 \mathrm{ml} / \mathrm{min}$. The solvent mixture was degassed in an ultrasonic bath before to be used as mobile phase. The concentration of the phenolic acids was determined from standard curves made with known concentrations of each compound. The response of the UV detector was recorded and integrated using the D-7000 HPLC System Manager software (Hitachi).

\subsection{Statistical analyses}

The influence of the variables methanol concentration, solvent/ solid ratio, and time on the extraction of antioxidant phenolic 
Table 2

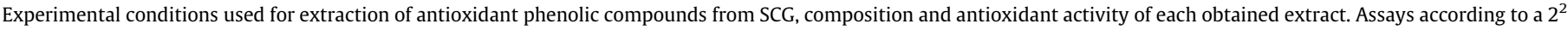
central composite design.

\begin{tabular}{|c|c|c|c|c|c|c|c|}
\hline \multirow[t]{2}{*}{ Assay } & \multicolumn{2}{|c|}{ Process variables - real and (coded) values } & \multicolumn{5}{|l|}{ Responses $^{\mathrm{a}}$} \\
\hline & $\begin{array}{l}\text { Methanol concentration } \\
(\%)\end{array}$ & $\begin{array}{l}\text { Solvent/solid ratio (ml/ } \\
\mathrm{g})\end{array}$ & $\begin{array}{l}\text { TP (mg GAE/ } \\
\text { g SCG) }\end{array}$ & $\begin{array}{l}\text { FLA (mg QE/ } \\
\text { g SCG) }\end{array}$ & $\begin{array}{l}\text { CGA (mg/ } \\
\mathrm{g} \mathrm{SCG})\end{array}$ & $\begin{array}{l}\text { PCA (mg/ } \\
\text { g SCG) }\end{array}$ & $\begin{array}{l}\text { FRAP (mM Fe(II)/ } \\
\text { g SCG) }\end{array}$ \\
\hline 1 & $20(-1)$ & $10(-1)$ & 7.3 & 0.86 & 0.37 & 0.06 & 0.056 \\
\hline 2 & $80(+1)$ & $10(-1)$ & 6.6 & 1.55 & 0.68 & 0.09 & 0.043 \\
\hline 3 & $20(-1)$ & $40(+1)$ & 10.5 & 1.17 & 1.33 & 0.24 & 0.086 \\
\hline 4 & $80(+1)$ & $40(+1)$ & 11.4 & 2.50 & 1.39 & 0.25 & 0.097 \\
\hline 5 & $20(-1)$ & $25(0)$ & 9.0 & 1.07 & 1.27 & 0.20 & 0.078 \\
\hline 6 & $80(+1)$ & $25(0)$ & 9.0 & 2.09 & 1.39 & 0.21 & 0.089 \\
\hline 7 & $50(0)$ & $10(-1)$ & 11.0 & 0.75 & 0.51 & 0.07 & 0.048 \\
\hline 8 & $50(0)$ & $40(+1)$ & 16.3 & 1.62 & 1.16 & 0.21 & 0.102 \\
\hline 9 & $50(0)$ & $25(0)$ & 17.8 & 1.36 & 0.99 & 0.17 & 0.087 \\
\hline 10 & $50(0)$ & $25(0)$ & 17.9 & 1.38 & 0.96 & 0.15 & 0.086 \\
\hline 11 & $50(0)$ & $25(0)$ & 18.2 & 1.38 & 0.98 & 0.15 & 0.086 \\
\hline 12 & $\mathrm{H}_{2} \mathrm{O}$ & 10 & 6.0 & 0.51 & 0.58 & 0.09 & 0.045 \\
\hline 13 & $\mathrm{H}_{2} \mathrm{O}$ & 40 & 7.4 & 0.56 & 0.57 & 0.09 & 0.040 \\
\hline
\end{tabular}

a TP: total phenolics; FLA: flavonoids; CGA: chlorogenic acid; PCA: protocatechuic acid; FRAP: antioxidant activity by the ferric reducing antioxidant power assay.

compounds from SCG was investigated through a $2^{3}$ full factorial design and a $2^{2}$ central composite design. The real and coded values of the variables for the experimental designs are given in Tables 1 and 2 . Statistical significance of the variables was determined at the $5 \%$ probability level $(p<0.05)$. The data obtained from the $2^{2}$ experimental design were fitted to second order polynomial equations and where possible the models were simplified by elimination of statistically insignificant terms. Statistical significance of the regression coefficients was determined by Student's $t$ test, and the proportion of variance explained by the models were given by the multiple coefficient of determination, $R^{2}$. Statistical analysis of the data as well as the determination of the conditions able to maximize the extraction results were performed using the softwares Statistica (version 8.0), and Design expert (version 5.0). Assays to validate the optimum extraction conditions as well as the analysis for characterization of the produced extracts were performed in triplicate.

\section{Results and discussion}

The solvent concentration, solvent/solid ratio, extraction time, and temperature are key factors in extraction processes, as they affect both the kinetics of phenolics release from the solid matrix and the antioxidant activity of the extract. Therefore, this study consisted in evaluating the effect of these variables, namely the solvent concentration, solvent/solid ratio, and time on the recovery of antioxidant phenolic compounds from SCG. The temperature of extraction was fixed between 60 and $65^{\circ} \mathrm{C}$, considering the boiling point of the methanol $\left(64.7^{\circ} \mathrm{C}\right)$. The results obtained in these experiments are shown in Table 1 . Statistical analysis of these data revealed a significant influence $(p<0.05)$ of all the studied variables on the extraction results (total phenolics and antioxidant activity), which were improved when the methanol concentration was decreased, and the solvent/solid ratio and time were increased. In fact, the best results of total phenolics and FRAP were achieved in the conditions of the assay 7 that used methanol in a concentration of $60 \%$ and in a ratio of $30 \mathrm{ml}$ per $\mathrm{g}$ SCG, during 90 min (Table 1 ).

Aiming to maximize the extraction results and to define the best conditions for antioxidant phenolic compounds extraction from SCG, a new experimental design was proposed. In this new design, only the methanol concentration and the solvent/solid ratio were studied. The extraction time was fixed at $90 \mathrm{~min}$ since the use of longer times could not be economically advantageous. Methanol concentration was then varied between $20 \%$ and $80 \%$, and the solvent/solid ratio between 10 and $40 \mathrm{ml} / \mathrm{g}$ SCG. Extraction conditions used in each experimental assay and the respective total phenolics content and antioxidant activity of the obtained SCG extracts are shown in Table 2. For comparison, assays using only distilled water as extraction solvent were also performed; however, the use of methanol as solvent gave better extraction results than the use of only water. This could be explained by the fact that phenolic compounds are often more soluble in organic solvents less polar than water $[16,20]$. Alcohols, particularly methanol and ethanol, were also more efficient than water in extracting phenolics from different natural sources such as citrus peel, black tea, barley, mashua tubers, and medicinal plants [15,21-23]. However, methanol is considered the best solvent for polyphenols extraction [24].

In the second experimental design, the highest amount of phenolic compounds recovered by methanol extraction was correspondent to an average of $18 \mathrm{mg} \mathrm{GAE} / \mathrm{g}$ SCG (assays 9, 10 and 11, Table 2 ). This is a high value, analogous to the content reported in other important antioxidant sources such as ripe raspberry (12.0$15.3 \mathrm{mg}$ GAE/g dry matter), blackberry (12.1-14.8 mg GAE/g dry matter) [25], and almond shells (22.0 mg GAE/g dry matter) [26]. The antioxidant activity of the methanolic SCG extracts (varying from 0.043 to $0.102 \mathrm{mM} \mathrm{Fe(II)/g} \mathrm{SCG,} \mathrm{Table} \mathrm{2)} \mathrm{was} \mathrm{also} \mathrm{higher} \mathrm{than}$ the values reported to other natural sources such as apple, pear, peach, plum, and kiwi [27]. Chemical characterization of the SCG extracts revealed that all of them contained chlorogenic acid, protocatechuic acid and flavonoids in their composition (Table 2), compounds that are well described to have antioxidant capacity and numerous biofunctionalities $[9,28,29]$. The high content of phenolic compounds (with presence of phenolic acids and flavonoids) and antioxidant activity of SCG extracts reveal that SCG is a potential source to obtain antioxidant phenolic compounds.

The composition of the methanolic SCG extracts and their antioxidant activity strongly varied according to the extraction conditions used (Table 2). By varying the extraction conditions, the total phenolics and flavonoids contents, as well as the antioxidant activity of the extracts were increased in almost 3-fold. More significant variations were observed for the contents of chlorogenic and protocatechuic acids, which increased in the order of 4 -fold. These results demonstrate that the studied operational variables exerted great influence on the extraction of antioxidant phenolic compounds from SCG. In order to verify the effect of each operational variable in the responses, Pareto charts were plotted (Fig. 1). In this figure, bars extending beyond the vertical line corresponded to the effects statistically significant at $95 \%$ confidence level. As can be noted, both variables methanol concentration and solvent/solid ratio exerted significant influence $(p<0.05)$ in all the evaluated 

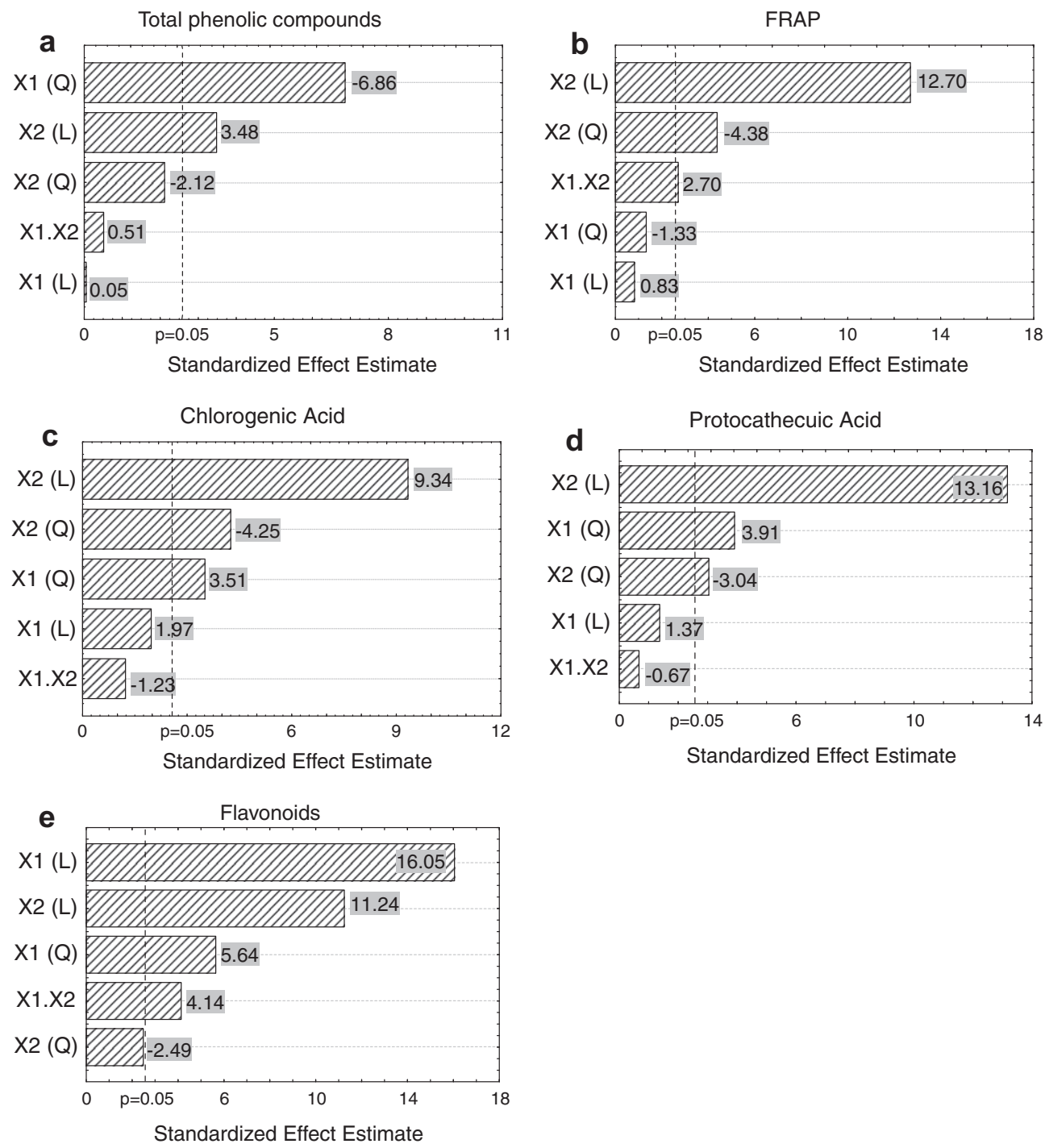

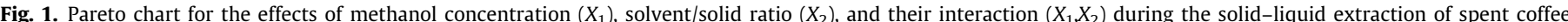

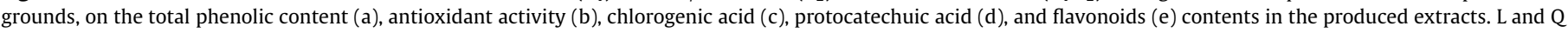
correspond to the effects at linear and quadratic levels, respectively.

Table 3

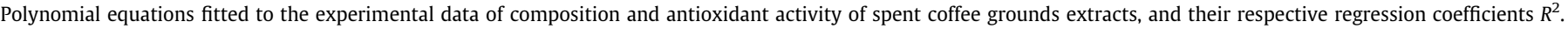

\begin{tabular}{|c|c|c|}
\hline Response & Model equation ${ }^{a}$ & $R^{2}$ \\
\hline Total phenolic compounds (TP, in mg GAE/g SCG) & $\mathrm{TP}=17.07-6.72 X_{1}^{2}+2.22 X_{2}-2.07 X_{2}^{2}$ & 0.94 \\
\hline Antioxidant activity (FRAP, in mM Fe(II)/g SCG) & $\mathrm{FRAP}=0.085+0.002 X_{1}+0.023 X_{2}-0.013 X_{2}^{2}+0.006 X_{1} X_{2}$ & 0.97 \\
\hline Chlorogenic acid (CGA, in mg/g SCG) & $\mathrm{CGA}=1.03+0.45 X_{1}^{2}+0.77 X_{2}-0.54 X_{2}^{2}$ & 0.91 \\
\hline Protocatechuic acid (PCA, in mg/g SCG) & $\mathrm{PCA}=0.16+0.04 X_{1+} 0.08 X_{2}-0.03 X_{2}^{2}$ & 0.96 \\
\hline Flavonoids (FLA, in mg QE/g SCG) & $\mathrm{FLA}=1.30+0.51 X_{1}+0.24 X_{1}^{2}+0.36 X_{2}+0.16 X_{1} X_{2}$ & 0.97 \\
\hline
\end{tabular}

${ }^{\text {a }} X_{1}$ : methanol concentration; $X_{2}$ : solvent/solid ratio. Coded values.

responses. The solvent/solid ratio was the most important variable affecting the antioxidant activity of the extracts (Fig. 1b), as well as the extraction of chlorogenic and protocatechuic acids (Fig. 1c and d); whereas methanol concentration was the main variable responsible for the extraction of phenolic compounds and flavonoids (Fig $1 \mathrm{a}$ and $\mathrm{e}$ ). The methanol concentration was also an important variable contributing to the extraction of phenolic compounds from other natural sources, such as mashua tubers, for example [15].
Mathematical models describing the responses variations as a function of the variations in the methanol concentration and solvent/solid ratio were established (Table 3 ). Where possible, the models were simplified by elimination of statistically insignificant terms (with $p>0.05$ ). All the models were established with high coefficient of determinations $R^{2}$, ranging from 0.91 to 0.97 , which means a close agreement between the experimental results and those predicted by the models. These models could efficiently be used for a rapid prediction of the extraction results to be achieved 
a

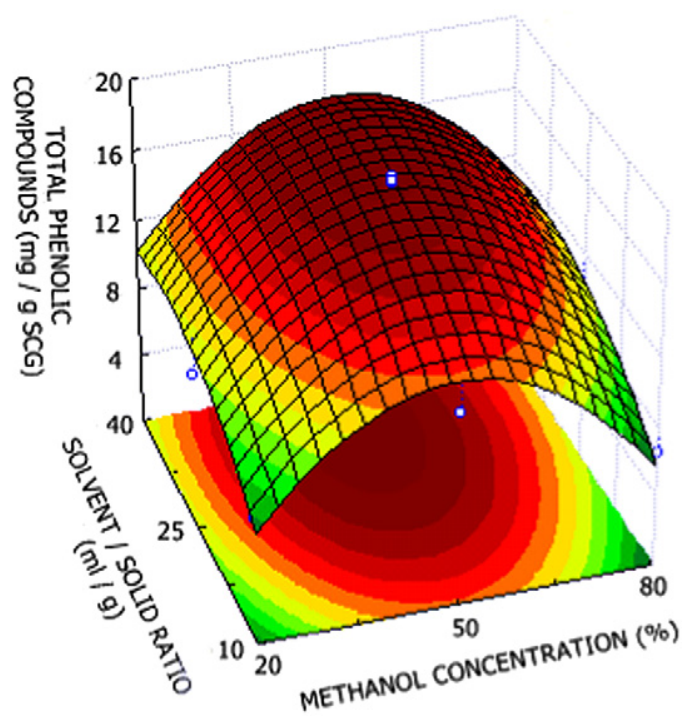

b

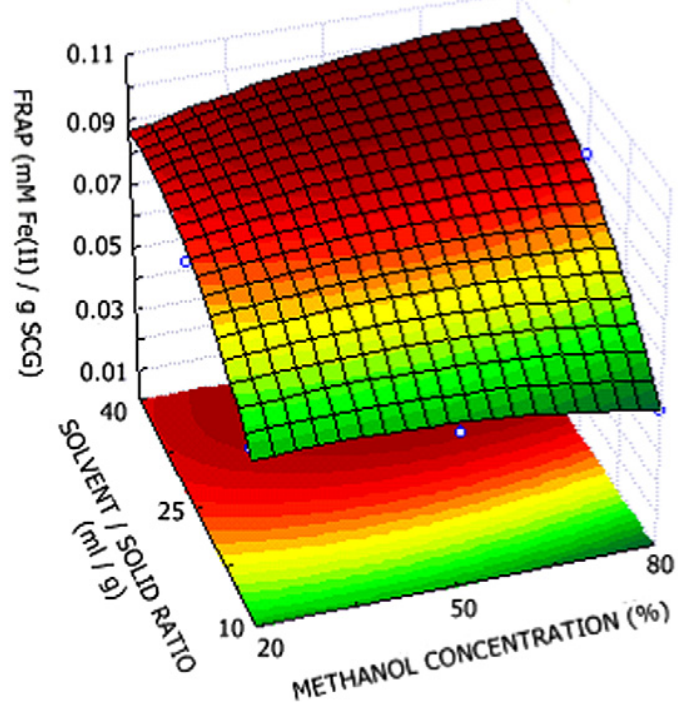

Fig. 2. Response surfaces described by the models representing the total phenolics content (a) and antioxidant activity FRAP (b) of spent coffee grounds extracts obtained by extraction with methanol. The variables are presented in their original levels.

when using methanol concentrations and solvent/solid ratios in the range of values here studied.

All the mathematical models describing the responses variations presented linear $(\mathrm{L})$ and quadratic $(\mathrm{Q})$ terms, since both variables levels presented statistical significance at $p<0.05$, as shown in Fig. 1. The quadratic term for methanol concentration was the most significant for the response of total phenolic compounds (Fig 1a) and presented a negative signal. This means that the extraction results were not linearly increased when the methanol concentration was decreased, but there was an optimum point after which the use of lower methanol concentrations did not improve the extraction results. Such behavior can be well visualized through the three-dimensional surface plot presented in Fig. 2a. This surface describes the variations of the response as a function of the variations of the variables, in the studied range of values. As can be observed, the solvent concentration decrease was beneficial for the extraction of phenolic compounds but up to attain a certain limit, after which the extraction efficiency was reduced. In fact, the use of water in combination with a organic solvent has been reported to contribute to the creation of a moderately polar medium that insures the extraction of phenolics, giving better results than when using a pure organic solvent $[15,30,31]$. On the other hand, the use of water as only solvent gives lower extraction values and yields, as before explained $[16,20]$.

A three-dimensional surface was also plotted for the results of antioxidant activity in SCG extracts (Fig. 2b). When comparing this plot with that obtained for the results of total phenolic compounds (Fig. 2a), it is possible to visualize that the region where the responses are maximized is not exactly the same in both figures. However it would be very useful to find an optimum extraction condition able to yield extracts with elevated content of phenolic compounds and antioxidant activity. Considering this aspect, a graphical optimization based on overlaying the curves of these two responses was conducted in order to establish an extraction condition to simultaneously maximize the total content of phenolic compounds and antioxidant activity of the SCG extracts. To find this optimum condition, the following criteria was imposed: total phenolic content $\geqslant 16 \mathrm{mg} \mathrm{GAE} / \mathrm{g}$ SCG, and FRAP $\geqslant 0.095 \mathrm{mM}$ $\mathrm{Fe}(\mathrm{II}) / \mathrm{g}$ SCG. The overlaying plot attained (Fig. 3) shows an area where the imposed criteria are satisfied. A point was assigned in this area (marked by the square) as optimum point, which corresponded to the use of a $60 \%$ methanol concentration in a solvent/ solid ratio of $40 \mathrm{ml} / \mathrm{g}$. Under these extraction conditions, SCG extracts with a total phenolic content of $16 \mathrm{mg} \mathrm{GAE} / \mathrm{g}$ SCG, and FRAP of $0.10 \mathrm{mM} \mathrm{Fe}(\mathrm{II}) / \mathrm{g} \mathrm{SCG}$, in the confidence range of $95 \%$, can be obtained. Similar methanol concentration (60\%) has also been used for extracting phenolic compounds from other natural sources, providing better extraction results than other methanol-water mixtures [32-35].

Assays to validate the optimum extraction conditions were performed and the results obtained for total phenolic compounds and antioxidant activity of the extract revealed a close agreement with the results predicted by the statistical analysis (Table 4). Additionally, the contents of flavonoids, chlorogenic and protocatechuic acids that can be obtained under these optimized conditions were also determined, and corresponded to $1.81 \mathrm{mg} \mathrm{QE} / \mathrm{g}$ SCG, $1.24 \mathrm{mg} / \mathrm{g}$ SCG, and $0.21 \mathrm{mg} / \mathrm{g} \mathrm{SCG}$, respectively.

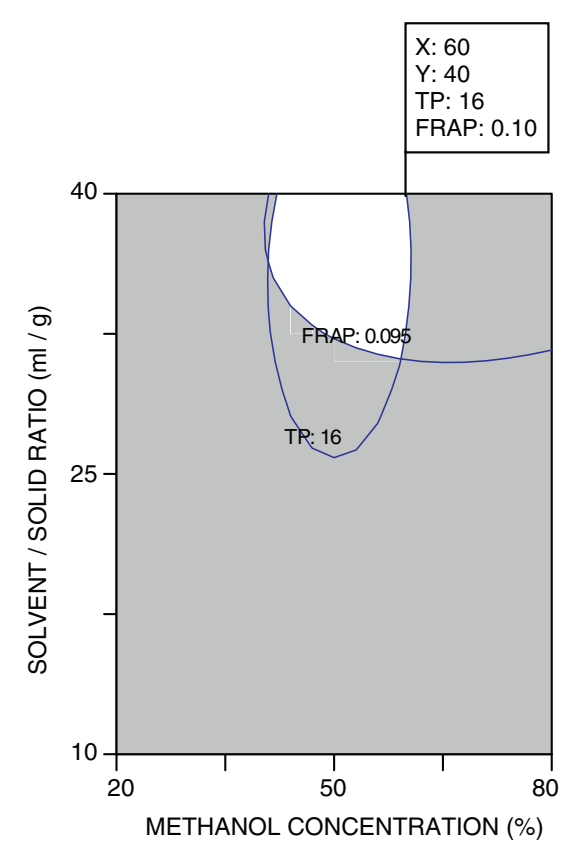

Fig. 3. Optimum region by overlaying the curves of the responses total phenolics content (TP) and antioxidant activity (FRAP) as a function of the methanol concentration and solvent/solid ratio used for spent coffee ground extraction. 
Table 4

Results obtained in the assays for validation of the conditions optimized for extraction of antioxidant phenolic compounds from spent coffee grounds.

\begin{tabular}{|c|c|c|c|c|}
\hline \multirow{2}{*}{$\begin{array}{l}\text { Assays for validation of } \\
\text { the optimized } \\
\text { conditions }\end{array}$} & \multicolumn{2}{|c|}{$\begin{array}{l}\text { Process variables - } \\
\text { optimum point values }\end{array}$} & \multicolumn{2}{|c|}{ Responses $^{\mathrm{a}}$} \\
\hline & $\begin{array}{l}\text { Methanol } \\
(\%)\end{array}$ & $\begin{array}{l}\text { Solvent/ } \\
\text { solid ratio } \\
(\mathrm{ml} / \mathrm{g})\end{array}$ & $\begin{array}{l}\text { TP } \\
(\mathrm{mg} \mathrm{GAE} / \\
\text { g SCG) }\end{array}$ & $\begin{array}{l}\text { FRAP } \\
(\mathrm{mM} \mathrm{Fe}(\mathrm{II}) / \\
\mathrm{g} \mathrm{SCG})\end{array}$ \\
\hline 1 & 60 & 40 & 16.0 & 0.108 \\
\hline 2 & 60 & 40 & 15.9 & 0.113 \\
\hline 3 & 60 & 40 & 16.1 & 0.106 \\
\hline Average & & & 16.0 & 0.109 \\
\hline $\begin{array}{l}\text { Results predicted by } \\
\text { the statistical } \\
\text { analysis }\end{array}$ & 60 & 40 & 16.0 & 0.100 \\
\hline
\end{tabular}

a TP: total phenolics; FRAP: antioxidant activity by the ferric reducing antioxidant power assay.

\section{Conclusions}

Solid-liquid extraction using methanol as organic solvent was an efficient method to extract antioxidant phenolic compounds from spent coffee grounds. The extraction of total phenolics, flavonoids, chlorogenic and protocatechuic acids, as well as the antioxidant activity of the produced extracts were affected by the methanol concentration, solvent/solid ratio, and extraction time used. Maximum value of phenolic compounds extracted from SCG were correspondent to $18 \mathrm{mg} \mathrm{GAE} / \mathrm{g} \mathrm{SCG}$, and were obtained when using a methanol concentration of $50 \% \mathrm{v} / \mathrm{v}$ in a ratio of $25 \mathrm{ml}$ per $\mathrm{g}$ of SCG, during $90 \mathrm{~min}$. Optimization of the extraction conditions (methanol concentration of $60 \%$ in a solvent/solid ratio of $40 \mathrm{ml} / \mathrm{g}$, during $90 \mathrm{~min}$ ) was useful to produce extracts containing simultaneously high content of phenolic compounds $(16 \mathrm{mg}$ GAE/g SCG, correspondent to an extraction yield of $89 \%$ considering the maximum phenolic compounds concentration found in SCG) and high antioxidant activity ( $0.10 \mathrm{mM} \mathrm{Fe}(\mathrm{II}) / \mathrm{g} \mathrm{SCG})$. Since antioxidant compounds provide health benefits, spent coffee grounds extracts could be of great interest for application in food and pharmaceutical products. However, it merits emphasizing that although methanol is the most commonly used extraction solvent due to its high polarity and high extraction yields, the toxic characteristic of this solvent arises serious issues when the purpose of the compounds extracted with this solvent is the application in food and pharmaceutical industries. To overcome this problem, the next step of our research work will be focused on finding other less or non-toxic solvents for extraction, able to promote high extraction results as methanol, or even using bioprocesses such as the solidstate fermentation, which do not require the application of any organic solvent. The use of methanol in the present study was useful to establish the maximum amount of phenolic compounds that was present in SCG, and also to verify the possibility of obtaining antioxidant phenolic extracts from this agro-industrial residue.

\section{Acknowledgment}

This work was supported by the Portuguese Foundation for Science and Technology (FCT).

\section{References}

[1] S.I. Mussatto, E.M.S. Machado, S. Martins, J.A. Teixeira, Production, composition and application of coffee and its industrial residues, Food Bioprocess Tech. 4 (2011) 661-672.

[2] T. Tokimoto, N. Kawasaki, T. Nakamura, J. Akutagawa, S. Tanada, Removal of lead ions in drinking water by coffee grounds as vegetable biomass, J. Colloid Interf. Sci. 281 (2005) 56-61
[3] S.I. Mussatto, L.M. Carneiro, J.P.A. Silva, I.C. Roberto, J.A. Teixeira, A study on chemical constituents and sugars extraction from spent coffee grounds, Carbohyd. Polym. 83 (2011) 368-374.

[4] A. Scalbert, I.T. Johnson, M. Saltmarsh, Polyphenols: antioxidants and beyond, Am. J. Clin. Nutr. 81 (2005) 215S-217S.

[5] C. Rice-Evans, N. Miller, G. Paganga, Antioxidant properties of phenolic compounds, Trends Plant. Sci. 2 (1997) 152-159.

[6] K. Ramalakshmi, L.J.M. Rao, Y. Takano-Ishikawa, M. Goto, Bioactivities of lowgrade green coffee and spent coffee in different in vitro model systems, Food Chem. 115 (2009) 79-85.

[7] P.S. Murthy, M.M. Naidu, Recovery of phenolic antioxidants and functional compounds from coffee industry by-products, Food Bioprocess Tech. (2010), doi:10.1007/s11947-010-0363-z.

[8] A. Farah, C.M. Donangelo, Phenolic compounds in coffee, Braz. J. Plant Physiol 18 (2006) 23-36.

[9] J. Shan, J. Fu, Z. Zhao, X. Kong, H. Huang, L. Luo, Z. Yin, Chlorogenic acid inhibits lipopolysaccharide-induced cyclooxygenase-2 expression in RAW264.7 cells through suppressing NF-kB and JNK/AP-1 activation, Int. Immunopharmacol. 9 (2009) 1042-1048.

[10] E. Cortazar, L. Bartolomé, A. Delgado, N. Etxebarria, L.A. Fernández, A. Usobiaga O. Zuloaga, Optimization of microwave-assisted extraction for the determination of nonylphenols and phthalate esters in sediment samples and comparison with pressurised solvent extraction, Anal. Chim. Acta. 534 (2005) 247-254

[11] M. Markom, M. Hasan, W.R.W. Daud, H. Singh, J.M. Jahim, Extraction of hydrolysable tannins from Phyllanthus niruri Linn.: effects of solvents and extraction methods, Sep. Purif. Technol. 52 (2007) 487-496.

[12] S. Martins, C.N. Aguilar, I. de la Garza-Rodriguez, S.I. Mussatto, J.A. Teixeira, Kinetic study of nordihydroguaiaretic acid recovery from Larrea tridentata by microwave-assisted extraction, J. Chem. Technol. Biotechnol. 85 (2010) 1142 1147

[13] M.T. Escribano-Bailón, C. Santos-Buelga, Polyphenol extraction from foods, in: C. Santos-Buelga, G. Williamson (Eds.), Methods in Polyphenol Analysis, The Royal Society of Chemistry, Cambridge, United Kingdom, 2003, pp. 1-16.

[14] M. Pinelo, A.G. Tress, M. Pedersen, A. Arnous, A.S. Meyer, Effect of cellulases solvent type and particle size distribution on the extraction of chlorogenic acid and other phenols from spent coffee grounds, Am. J. Food Technol. 2 (2007) 641-651.

[15] R. Chirinos, H. Rogez, D. Campos, R. Pedreschi, Y. Larondelle, Optimization of extraction conditions of antioxidant phenolic compounds from mashua (Tropaeolum tuberosum Ruíz \& Pavón) tubers, Sep. Purif. Technol. 55 (2007) 217-225.

[16] D.-O. Kim, C.Y. Lee, Extraction and isolation of polyphenolics, Curr. Protoc. Food Anal. Chem. (Suppl. 6) (2002) I1.2.1-I1.2.12.

[17] V.L. Singleton, J.A. Rossi Jr., Colorimetry of total phenolics with phosphomolybdic-phosphotungstic acid reagents, Am. J. Enol. Vitic. 16 (1965) 144-158.

[18] C.-C. Chang, M.-H. Yang, H.-M. Wen, J.-C. Chern, Estimation of total flavonoid content in propolis by two complementary colorimetric methods, J. Food Drug Anal. 10 (2002) 178-182.

[19] I.F.F. Benzie, J.J. Strain, The ferric reducing ability of plasma (FRAP) as a measure of "antioxidant power": the FRAP assay, Anal. Biochem. 239 (1996) 70-76.

20] F.F Liu, C.Y Ang D Springer, Optimization of extraction conditions for active components in Hypericum perforatum using response surface methodology, J. Agric. Food Chem. 48 (2000) 3364-3371.

[21] N. Turkmen, F. Sari, Y.S. Velioglu, Effects of extraction solvents on concentration and antioxidant activity of black mate tea polyphenols determined by ferrous tartrate and Folin-Ciocalteu methods, Food Chem. 99 (2006) 835-841.

[22] Z.-U. Rehman, Citrus peel extract - A natural source of antioxidant, Food Chem. 99 (2006) 450-454

[23] P. Jamal, A.A. Barkat, A. Amid, Distribution of phenolics in various Malaysian medicinal plants, J. Applied Sci. 10 (2010) 2658-2662.

[24] I.H. Adil, H.I. Cetin, M.E. Yener, A. Bayindirli, Subcritical (carbon dioxide + ethanol) extraction of polyphenols from apple and peach pomaces, and determination of the antioxidant activities of the extracts, J. Supercrit. Fluids 43 (2007) 55-63.

[25] S.Y. Wang, H.-S. Lin, Antioxidant activity in fruits and leaves of blackberry, raspberry, and strawberry varies with cultivar and developmental stage, J. Agric. Food Chem. 48 (2000) 140-146.

[26] A. Moure, M. Pazos, I. Medina, H. Domínguez, J.C. Parajó, Antioxidant activity of extracts produced by solvent extraction of almond shells acid hydrolysates, Food Chem. 101 (2007) 193-201.

[27] P. Stratil, B. Klejdus, V. Kubán, Determination of phenolic compounds and their antioxidant activity in fruits and cereals, Talanta 71 (2007) 17411751.

[28] P. Vitaglione, G. Donnarumma, A. Napolitano, F. Galvano, A. Gallo, L. Scalfi, V. Fogliano, Protocatechuic acid is the major human metabolite of cyanidinglucosides, J. Nutr. 137 (2007) 2043-2048.

[29] E. Middleton Jr., C. Kandaswami, T.C. Theoharides, The effects of plant flavonoids on mammaliam cells: implications for inflammation, heart disease and cancer, Pharmacol. Rev. 52 (2000) 673-751.

[30] K.H. Musa, A. Abdullah, K. Jusoh, V. Subramaniam, Antioxidant activity of pinkflesh guava (Psidium guajava L.): effect of extraction techniques and solvents, Food Anal. Methods 4 (2011) 100-107. 
[31] B. Lapornik, M. Prosek, A.G. Wondra, Comparison of extracts prepared from plant by-products using different solvents and extraction time, J. Food Eng. 71 (2005) 214-222.

[32] Y. Yilmaz, R.T. Toledo, Oxygen radical absorbance capacities of grape/wine industry byproducts and effect of solvent type on extraction of grape polyphenols, J. Food Compos. Anal. 19 (2006) 41-48.

[33] A. Arnous, A.S. Meyer, Comparison of methods for compositional characterization of grape (Vitis vinifera $L$.) and apple (Malus domestica) skins, Food Bioprod. Process. 86 (2008) 79-86.
[34] Z.Y. Ju, L.R. Howard, Effects of solvent and temperature on pressurized liquid extraction of anthocyanins and total phenolics from dried red grape skin, J. Agric. Food Chem. 51 (2003) 5207-5213.

[35] C. Proestos, M. Komaitis, Ultrasonically assisted extraction of phenolic compounds from aromatic plants: comparison with conventional extraction technics, J. Food Quality 29 (2006) 567-582. 